\title{
COMPARATIVE AND PERFORMANCE ANALYSIS OF INDUCTION MOTOR WITH ANN CONTROLLER
}

\author{
1 Durairaj S. 2 Dr.Y.Robinson, 3 Dr. M.Muthuramalingam \\ 1.Assistant Profrssor Tamilnadu engineering College, Coimbatore, India. \\ mathusafalt@gmail.com
}

2. Director.RVS Technical campus, Coimbatore. India.

3.Professor, Suguna College of Engineering, Coimbatore. India

\section{ABSTRACT}

A novel design of an adaptive artificial neural network technique (ANN) for controlling of the essential parameters, like as speed, torque, flux, voltage, current, and power etc of the induction motor is presented in this paper. Induction motors are characterized by way of incredibly non-linear, complicated and time-various dynamics and inaccessibility of its states and outputs for measurements. Thus it can be considered as a challenging engineering difficulty in the industrial sector. A few of them, such as PI, fuzzy strategies, Fuzzy logic based controllers are regarded as capability candidates for such application for operating induction motor. Hence of which, the outcome of the controller is also random and high-rated results are probably not obtained. Resolution of the proper rule base application upon the drawback can be achieved by the use of an ANN controller, which becomes a built-in system of method for the manipulate purposes and yields results, which is the focus of this paper. Within the designed ANN scheme, neural community tactics are used to prefer an appropriate rule base, which is utilizing the back propagation algorithm. The simulation outcome provided on this paper is exhibit the effectiveness of the developed approach, which has acquired faster response time or settling times. Additionally, the procedure developed has got a huge number of benefits within the industrial sector will also be converted into a real time application making use of some interfacing cards.

\section{Keywords: PI, ANN, Controller, Simulink, Induction motor, Parameter.}

\section{INTRODUCTION:}

Intelligent, self-studying or self-learning controls are operates with expert techniques, artificial intelligence, fuzzy logic, neural networks, hybrid networks, and many others have been newly recognized as the fundamental instruments to strengthen the efficiency of the power electronics based drive systems in the industrial sectors. Combination of this smart control with the addictiveness are seems in these days as probably the most promising study field within the practical implementation \& control of electrical drives. The design and implementation of control programs ordinarily depends on quantitative mathematical models of the plants (say, induction motors, Alternators, DC motors, and many others), the controllers, and so on. Every now and then, nevertheless, we encounter issues for which controller design becomes very complicated and costly to entertain. In such instances, it is most cases to become aware of human specialists or skilled operators of the plants or methods and realize ideas governing their moves for automatic control process [33]. ]. On this context, the fuzzy logic concepts coupled with artificial neural networks play a very predominant position in constructing the controllers for the plant. Induction motors play a important role within the industrial sector notably in the area of electric drives \& control. Without suitable controlling of the speed of the drive, it is very inconceivable to obtain the favored response for a specific application. AC motors, especially the squirrel-cage induction motors (SCIM), enjoy a number of inherent advantages like simplicity, reliability, low cost and virtually maintenance-free electrical drives. As a result, performance deteriorates and a conventional controller equivalent to a PID is unable to keep sufficient efficiency under these conditions. Now a days, there has been identifying an increasing interest in combining artificial intelligent control tools with conventional techniques [42].

The foremost motivations for such a hybrid implementation is that with fuzzy logic, neural networks \& rough sets of issues like uncertainty or unknown variants in plant parameters and structure can be dealt with additional effectiveness, thus making improvements to the robustness of the control system. Conventional control systems like PI, PID control had been used and the vector control approaches, for the speed control of induction machines through doing by many researchers [6]. The most important drawbacks of the linear control strategies are the sensitivity in performance to the process parameters variations and insufficient rejection of outside perturbations and load changes [8]. Induction motors are broadly used in various industries as important work-horses to produce rotational motions and forces. Moreover, traditional computation of system mathematical model is difficult or unattainable. Moreover, the design and tuning of conventional controller increases the implementation cost and provides further complexity within the control system \& therefore, may just reduce the reliability of the system control. In recent years, fuzzy logic has met a developing interest in number of motor control functions due to its non-linearity's dealing with component and independence of the plant modeling. The fuzzy logic controller (FLC) operates in a knowledge potential method, and its advantage relies on a set of linguistic if-then rules, like a human operator. There are a many technology methods are available for induction motors such as including scalar control, vector or field-oriented control, direct torque and flux control, sliding model control, and the adaptive control [11]. These control system leads restricted speed accuracy particularly in the low range speed and poor dynamic torque response. ]. A process to use the advanced V/f control for high voltage induction motors \& its stability used to be proposed. [9]. The scalar controlled motor drive, which is contrast to vector or field-oriented controlled, is not convenient to 
put into effect; however it shows relatively inferior efficiency. This control process provides restrained speed accuracy particularly within the low range speed and poor dynamic torque response.

In this paper, we changed the conventional PI controller through the ANN controller in speed controller loop. ANN which tunes the back propagation algorithm based on a collection of input-output information from $\mathrm{v} / \mathrm{f}$ control is applied in this method. In this paper, a sincere attempt is made to scale down the settling time of the responses \& make the velocity of response very speedy with the aid of designing an effective controller utilizing ANN control approach. The proper rule base is chosen utilizing an intelligently developed back propagation algorithm. Here, we have formulated this complicated control strategy for the speed maintaining of IM, which has yielded agreeable outcome compared to the others mentioned in the above literature survey. The results of our work have showed an extremely low transient response and a nonoscillating steady state response with - excellent stabilization.

\section{MODELLING OF INDUCTION MOTOR}

To operate the electric drive like motor by using power electronics control method is to be initiated only with the mathematical model of the plant. Additionally this mathematical model is required to further design for any type of controller to control the operation of the plant. Because of the above stated factors, an induction motor model was designed with the following parameters such as rotating field $(d, q)$ field reference (without saturation) concept [56]. The power circuit of the three phase induction motor is shown in the Fig. 1.

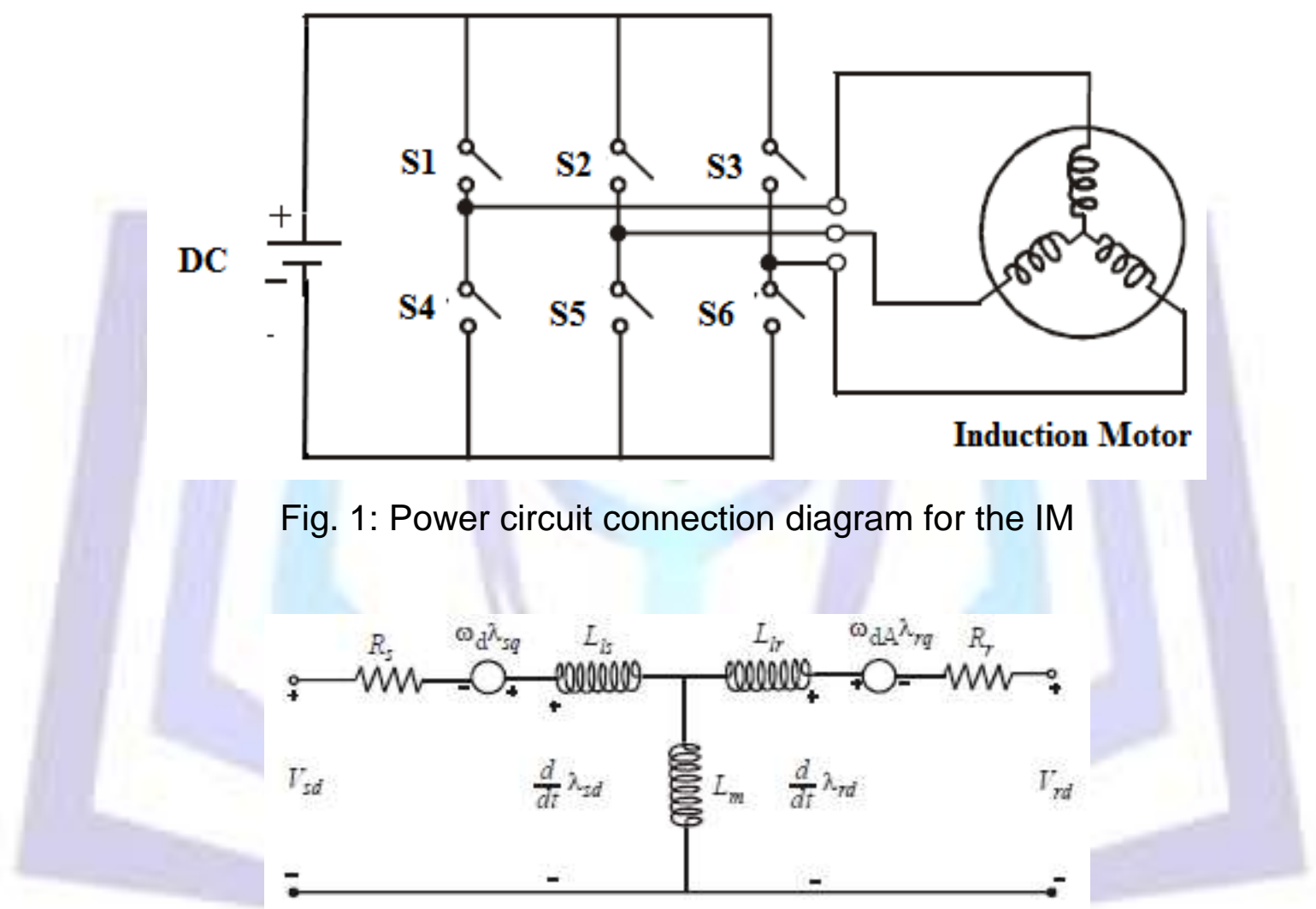

(a) $d$-axis

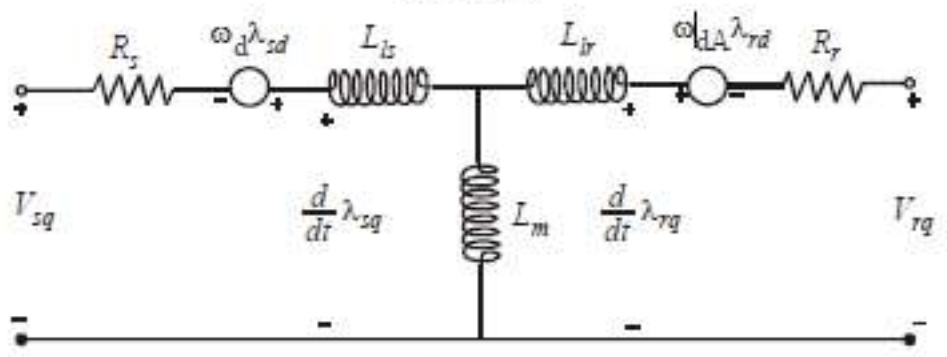

(b) $q$-axis

Fig. 2: Equivalent circuit of induction motor in $d$ - $q$ frame

The equivalent circuit used for acquire the mathematical model of the induction motor is shown in the Fig. 2. An induction motor equivalent circuit model is then used to calculate the voltage required to drive the flux, torque $\&$ the speed to the 
require values. This calculated voltage is then synthesized using the space vector modulation. The stator \& rotor voltage equations are given by [56]

$$
\begin{aligned}
& V_{s d}=R_{s i s} i_{s d}+\frac{d}{d t} \lambda_{s d}-\omega_{d} \lambda_{s q} \\
& V_{s q}=R_{s} i_{s q}+\frac{d}{d t} \lambda_{s q}-\omega_{d} \lambda_{s d} \\
& V_{r d}=R_{s} i_{r d}+\frac{d}{d t} \lambda_{r d}-\omega_{d A} \lambda_{r q}
\end{aligned}
$$

$$
V_{r q}=R_{s} i_{r q}+\frac{d}{d t} \lambda_{r q}-\omega_{d A^{\lambda}} \lambda_{r d}
$$

where $V_{s d}$ and $V_{s q}, V_{r d}$ and $V_{r q}$ are the direct axes \& quadrature axes stator and rotor voltages [56].

$$
\left[\begin{array}{l}
\lambda_{s d} \\
\lambda_{s q} \\
\lambda_{r d} \\
\lambda r q
\end{array}\right]=M\left[\begin{array}{l}
i_{s d} \\
\lambda_{s q} \\
\lambda_{r d} \\
\lambda_{r q}
\end{array}\right]_{s} ; M=\left[\begin{array}{cccc}
L_{s} & 0 & L_{m} & 0 \\
0 & L_{s} & 0 & L_{m} \\
L_{m} & 0 & L_{r} & 0 \\
0 & L_{m} & 0 & L_{r}
\end{array}\right]
$$

The squirrel-cage induction motor is taken as reference for the simulation study of this paper, it has the $d$ and $q$-axis components of the rotor voltage zero. The flux linkages with the currents are related by the electrical part of an induction motor can be described by a fourth-order state space model which is given by combining equations (1) - (5) as where ' $s$ ' is the laplacian operator. By superposition, i.e., adding the torques acting on the d-axis and the q-axis of the rotor windings, the instantaneous torque produced in the electromechanical interaction is given by Equation (6).

$$
T_{e m}=\frac{3}{2}\left(\frac{P}{2}\right)\left(\lambda_{r q} i_{r d}-\lambda_{r d} i_{r q}\right)
$$

(6)

The mechanical part of the motor is modeled by the equation (7).

$\frac{d}{d t} \omega_{m e c h}=\frac{T_{e m}-T_{l}}{J_{c q}}$

\section{(7)}

\section{Where}

\section{$J_{e q}=$ moment of inertia,}

This IMs mathematical model is further used to design a adaptive controller using ANN control strategy in the next chapter. The induction motor can be realized as an arrangement of merge the electric and magnetic circuits, which are coupled magnetically and electrically. 


\section{CONTROLLER DESIGN}

\subsubsection{PI Voltage-frequency controller}

The most common way to control the motor's shaft speed is to varying y the input supply frequency with constant voltage by using frequency converter in the system. If the induction motor is supplied with its rated voltage and proper frequency, the induced flux will be at the optimum design value, at the same tine the induction motor draws the specified current and delivers the rated torque at the relevant rated speed. When the load is increased (over-rated load), while running at base speed, the motor speed reduced and the slip increases. As has been presented in the earlier section, the motor can develop up to 2.5 times the rated torque with nearly $20 \%$ drop in the speed. Any further increase of load on the motor shaft can stall the motor. During the operation if we reducing the supply frequency below the rated value with maintaining constant rated supply voltage will cause an increase in motor magnetic flux. During the operation if the frequency is increased above its rated value, the magnetic flux and hence torque will decrease. The why the Fig. 3 illustrates the effect on the motor torque/speed characteristic as the operating frequency is varied with constant supply voltage applied [16].

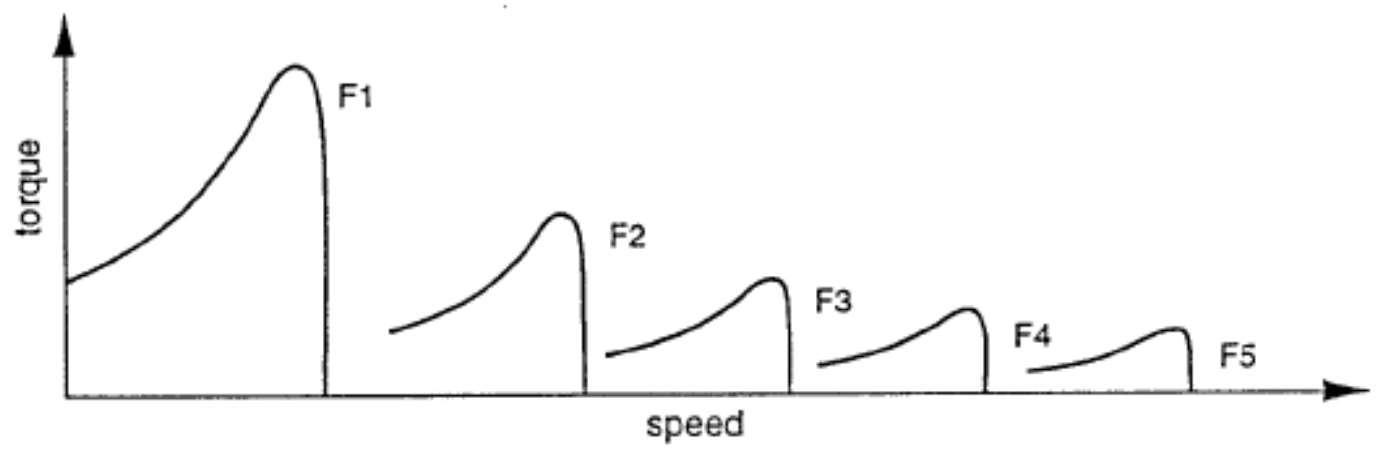

Figure 3: Torque/speed characteristic curve due to variable frequency and constant voltage

3.1.2. The mechanical torque developed by the induction motor is directly proportional to the magnetic field produced by the coil in the stator. The product of stator magnetic flux with magnetic angular velocity is directly proportional to the applied voltage of the stator coil. This makes the flux produced by the stator is proportional to the ratio of applied voltage and frequency of electrical supply. By varying the frequency, the speed of the motor can be varied. Therefore, by varying the voltage and frequency at the same ratio, flux and hence, the torque can be kept constant throughout the speed range.

$$
V \alpha \phi * 2 \pi f
$$

\section{$V \alpha V / F$}

The motor fed with a variable frequency of the power supply, the motor impedance will modify with the frequency, which influencing the magnetic flux produced at the motor air gap. Since the effectiveness of the torque produced in the motor is a function of the air gap magnetic flux. It is necessary to compensate for the motor impedance variations by changing the applied voltage to the motor for maintain a constant flux over the operating frequency range. This is achieved by increasing the motor voltage ' $\mathrm{Vs}$, at the lower frequencies and is termed 'voltage boost'. Fig.4 illustrates the effect of voltage boost on the motor torque/speed characteristic.

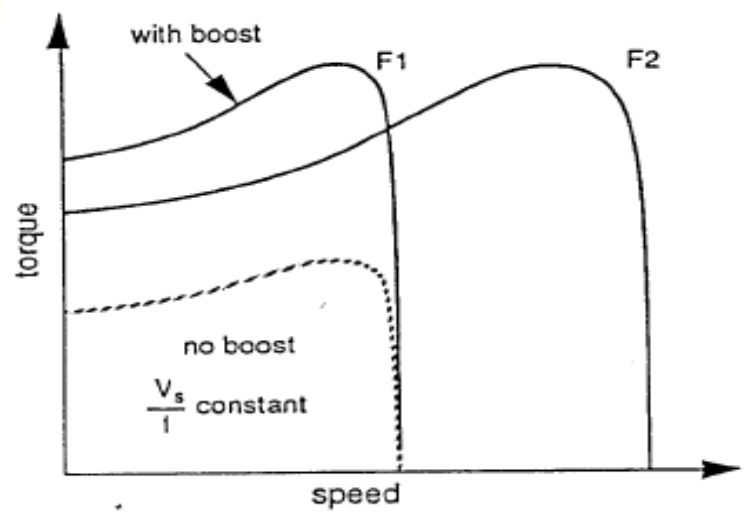

Figure 4: Torque/speed characteristic with constant V/F ratio. 
3.1.3 The Fig.5 shows the relation between the applied voltage and developed torque versus corresponding frequency of the power supply. This diagram demonstrates that 1,the voltage and frequency being increased up to the rated base speed 2, At the base speed, the applied voltage and corresponding frequency are reaching the rated values as listed in the nameplate or specification of the motor drive. 3, It is possible to drive the motor beyond base speed by increasing the frequency of the input supply. 4, however, the voltage applied to the motor cannot be increased beyond the specified rated voltage. 5, therefore, only the frequency can be increased, which results in the magnet field weakening and the torque available are being reduced. 6,Above base speed, the factors governing torque become complex, since friction and windage losses increase significantly at higher speeds. Hence, the torque curve becomes nonlinear with respect to speed or frequency [17].

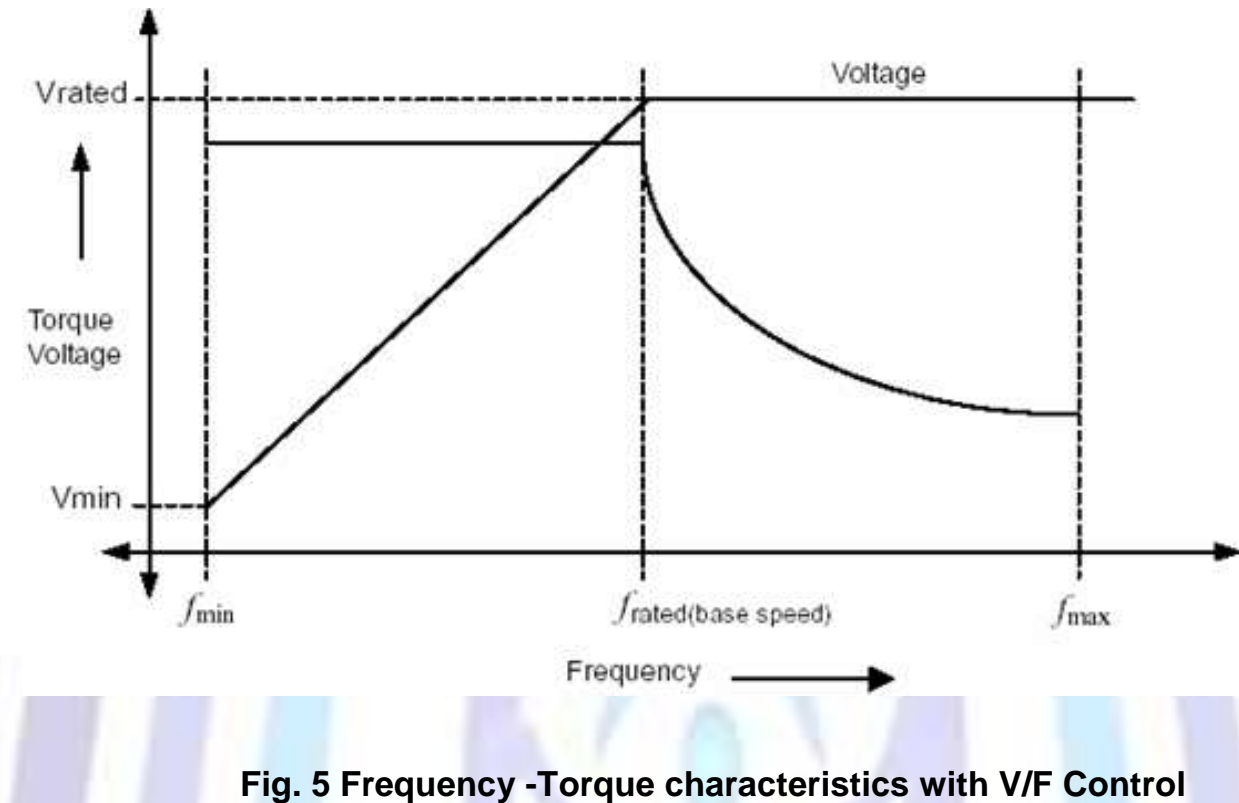

3.1.4. Space Vector Pulse Width Modulation (SVPWM) approach is one of the updated, computation-intensive PWM process and potentially suitable among the entire PWM approaches for variable frequency power drives and applications. Because of this reason and its advanced efficiency characteristics, it has been realizing that effective application is used everywhere in the recent years. This method is offered process control technique of the induction motors utilizing space vector pulse width modulation. The firing pulse generated with the aid of voltage magnitude and firing angle generated via reference speed of the motor. These procedures is very attractive, but suffer from one important drawback, viz., they are delicate to motor parametric modifications such as the rotor time constant and an inappropriate flux volume during estimation at lower speeds

\section{ANN CONTROLLER}

In this chapter, a brief assessment of the ANN principles for control, and the lot of motor process system parameters of the plant is provided. Neural networks have a potential to train with various parameter of induction motor. As a non-linear operation, they are able to be used for selection the immensely nonlinear system parameters with extreme accuracy. Also there had been some investigations into the application of NNs to power electronics and ac drives, together with speed estimation. This process gives rather excellent results of the speed and is powerful to parameter variation. Artificial Neural Network (ANN) is the model of the human brain that tries to imitate its learning procedure. It's an adaptive and wise approach that modification its foundation on input and output information. ANN model comprise of neurons in three layers such as input layer, hidden layer and output layers. The input layer is activated by way of feedback information, while the output layer sends information to an external device.

In our research work, a trained ANN is used to find the output magnitude of reference voltage and angle magnitude of voltage from the input of the motor speed (RPM). The output generate control gate signal by means of the space vector modulation controller for the induction motor. The ANN is used to estimate the most suitable reference voltage on real time, which corresponds to RPM of the motor. The info set used to train the ANN is obtained from PI controller outcome results. The operation of this process is defined and shown in the block diagram and configuration in figure 3.10 and 3.11 . The developed ANN configuration is a multilayer-perception structure along with an input layer, a hidden layer and output layer. The Motor RPM is the data with compose one node as input layer. The hidden layer is composed of twenty nodes whose operate is activated sigmoid. The output layer consists of ten nodes that is the best and viable voltage magnitude and angle 


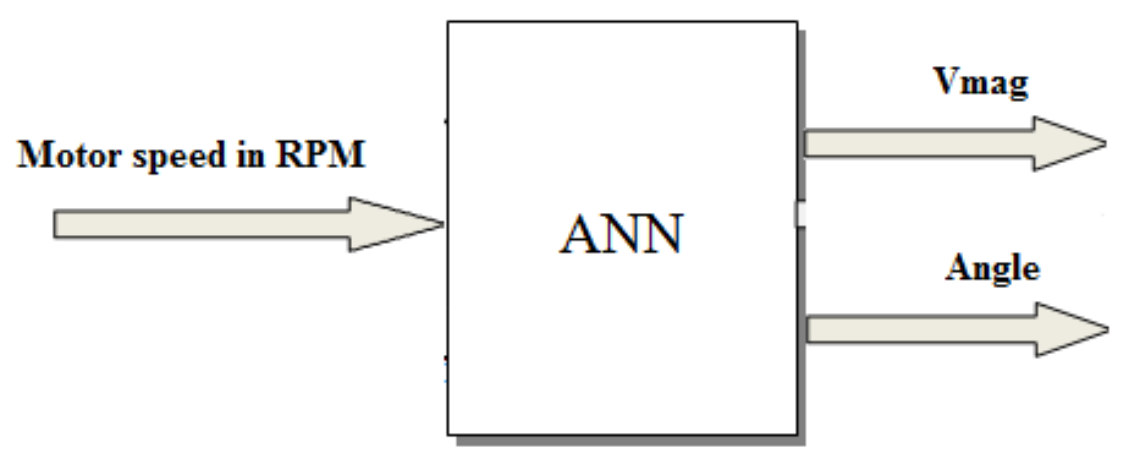

The ANN, In this work, data set consists of 3000 patterns of motor rpm, magnitude and angle variables, which have divided into two sub-databases. Out of these patterns, $70 \%$, of the samples are used to train the ANN, and the rest $30 \%$ are second-hand to test and validate the network. The performance is measured by calculating the mean- square error as shown in Equation (8).

$$
e=\frac{1}{p} \sum_{i=1}^{p}\left\|y^{(i)}-v^{(i)}\right\|^{2}
$$

(8)

Where,

$p=$ number of training data entries;

$y=$ ANN output vector;

$v=$ desired output.

For a set of input well-trained ANN would give as an output, which is very close to the desired value, giving an error almost zero. Each neuron $a_{j}$ computes a weighted sum of its $n$ inputs $V_{k}, k=1,2 \ldots n$, and generates an output as shown in Equation (9).

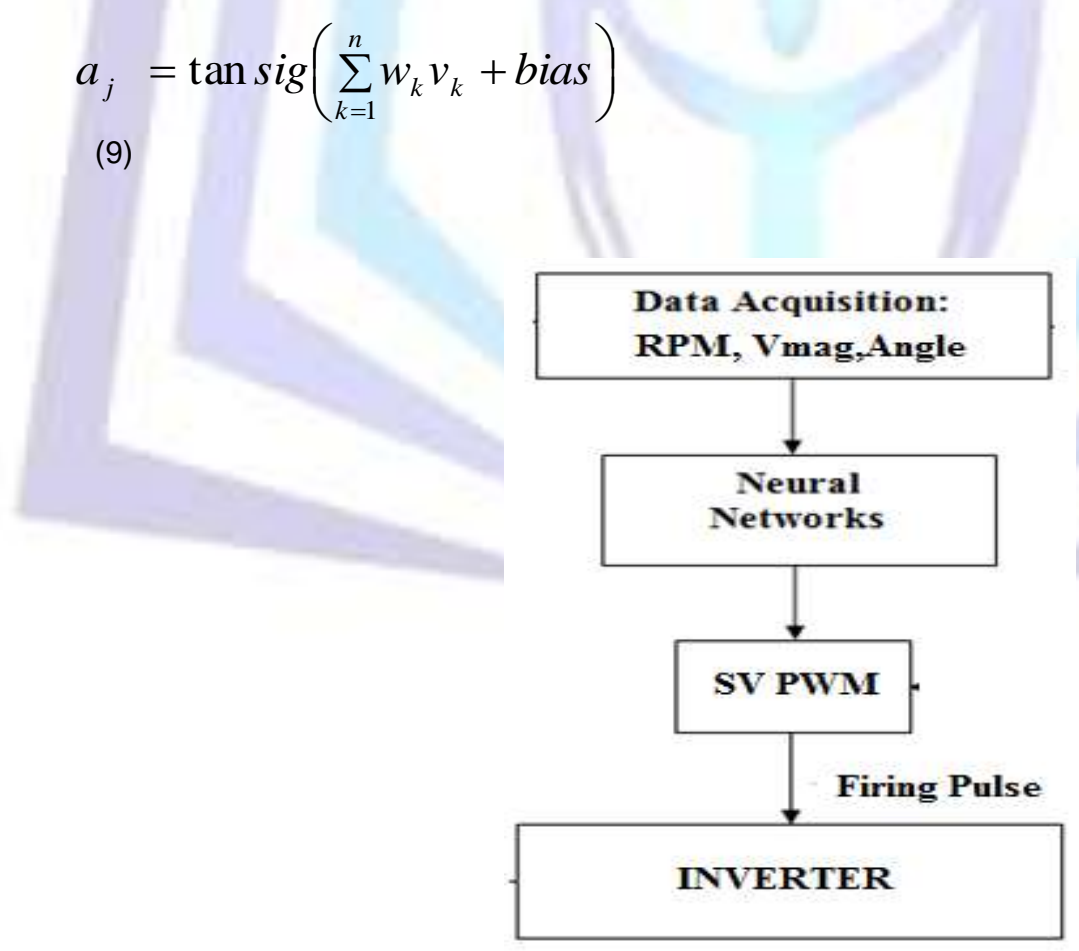

Fig.7 ANN Functional Block

The tan sigmoid function of the consequential weighted sum that regularly has a bias connected with it that can be considered as an additional input which provides the output. In Equation $9, w_{k}$ represents the synapse weight linked with each one of the $n$ inputs. These training sets select to cover all the distinctive input space in order to get good presentation. 


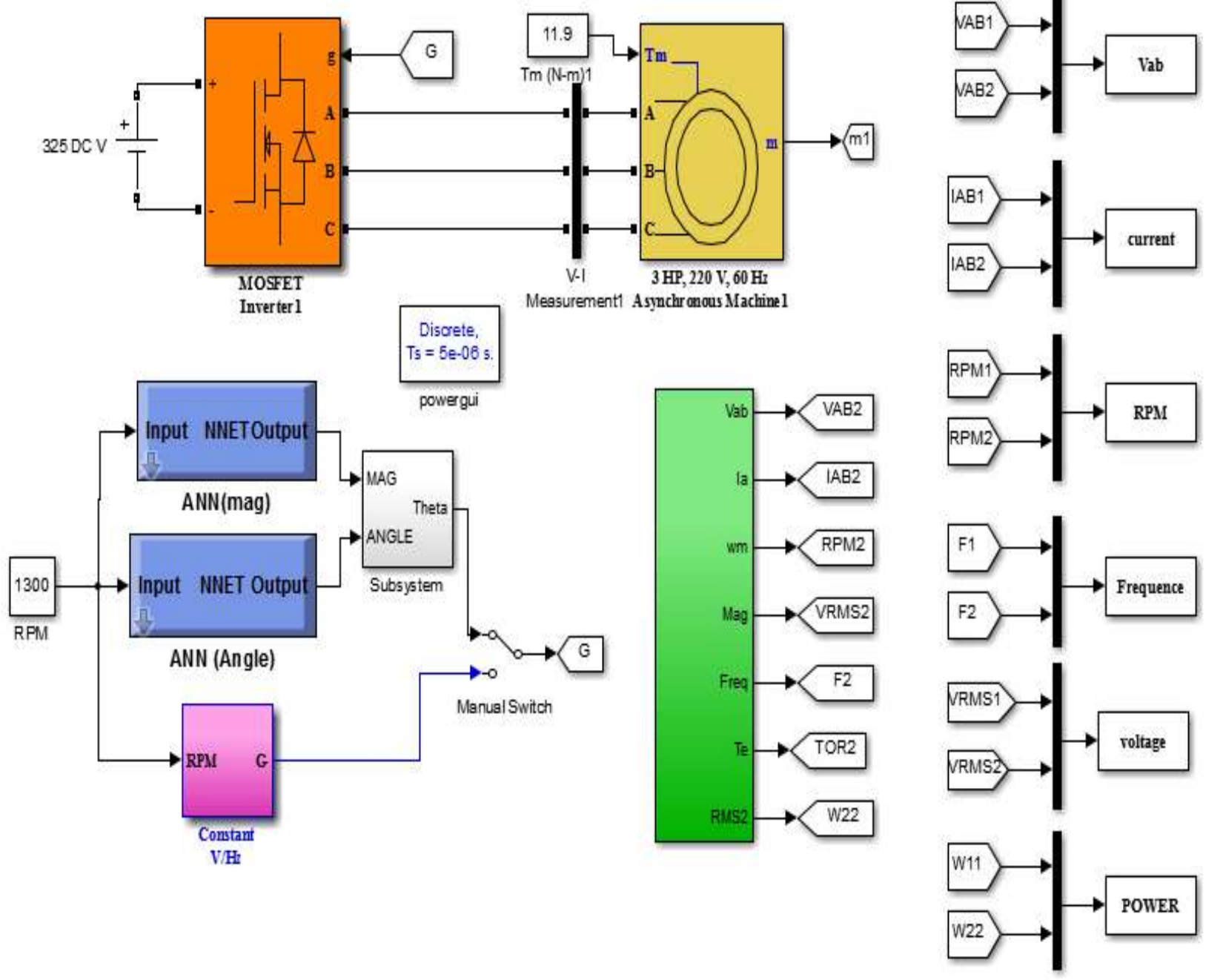

Fig..8 The developed simulink model for the speed control of

IM's using Artificial Neural Network (ANN)

\section{DEVELOPMENT OF SIMULINK MODEL}

Simulink model for the motor drive control developed in Matlab by using various parameters of the induction motor. This Simulink model with the ANN controller was developed by using variety of toolboxes available within the Simulink library such as the power, system, power electronics, control system, signal processing toolboxes and also from its general basic functions library. The complete approach modeled in Simulink in a control system which consisting of the controllers, samplers, comparators, , constants, gain blocks, multipliers, constant blocks, integrators, the output sinks, the input sources, work-space blocks, and so on. The developed Simulink model of the control for various type of parameters on the SCIM is shown in Fig. 8.

The simulation chopping frequency is set to $1980 \mathrm{~Hz}$ and the input of reference vector is Magnitude-angle. Speed control of the motor is carried out by using the constant voltage and frequency controller with addition to the proportional integrated block. The magnitude and frequency of the stator voltages are fixed on the basis of the speed set point. By means of varying the stator voltages magnitude in proportion with frequency, the stator flux is kept constant. The Threephase squirrel-cage motor rated $3 \mathrm{HP}, 220 \mathrm{~V}, 60 \mathrm{~Hz} ; 1725 \mathrm{rpm}$ is fed by way of a 3 phase MOSFET inverter connected to a DC voltage supply of $325 \mathrm{~V}$. The inverter is modeled utilizing the universal Bridge block and the motor by means of the Asynchronous machine block. The stator leakage inductance is about to twice its actual value. The reactor positioned between the inverter and the machine for achieve the smoothing effect. The load torque applied to the machine shaft is set to its nominal value of 11.9 N.M. The firing pulses to the inverter are generated by the space Vector PWM modulator. Due to the fact that the initial states have been automatically loaded, the simulation starts in steady state condition. When the motor reaches a constant speed of $1275 \mathrm{RPM}$, the stator voltage RMS value is down to $165.8 \mathrm{~V}$ and the frequency to 45.2 $\mathrm{Hz}$ 


\section{SIMULATION RESULTS \& DISCUSSIONS}

Simulink model with the PI v/f controller and ANN controller for the speed control of IM was developed in Matlab as shown in the Fig. 8. Simulations are run for a specific amount of time (say 1.5 secs) with conventional controller. After performing all the preliminary operations, the simulations are run for a period of 1.5 seconds in Matlab with a reference speed of 1300 RPM and with a load torque of $11.9 \mathrm{~N}-\mathrm{m}$. Once, the simulation is starts run, the various parameters such as speed, flux, torque, currents, voltage, power etc. gets automatically stored in the workspace in the Matlab package. Approximately 3000 data such as Input and output parameter of RPM and magnitude and angle are collected and stored. The collected values upload to the ANN fitting tool and the trained neural network (ANN) for analyzing and find the solution for the nonlinear system model like output voltage magnitude and output angle. The ANN is used to estimate the optimal value of all output parameter in real time, which corresponds to power at any given input reference speed.

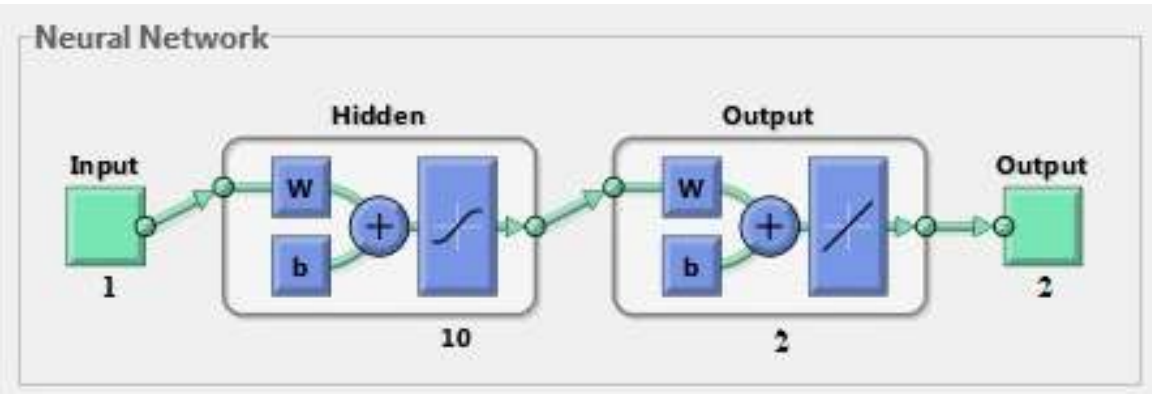

Fig.9.trained ANN structure

The developed ANN configuration is a multilayer-perception structure including an input layer, a hidden layer and output layer shown in Fig. 9. The input layer composed of two nodes in the input that are; the PV cell voltage and the current, the hidden layer is composed of twenty nodes whose function is activated sigmoid. The output layer is composed of one node that is the optimum reference voltage. In this work, database engaged consists of 3000 patterns of variables, which has divided into two sub-databases, $70 \%$, of the samples are used to train the ANN, and the rest $30 \%$ are second-hand to test and validate the network. The ANN output is further used to generate the firing pulse to be applied to the inverter bridge, which is further used to control the speed of the IM drive. From the simulation results shown in the Fig. 10 it is observed that, the response of the flux, slip, torque, terminal voltage, speed, currents, etc. takes lesser time to settle and reach the desired value compared conventional method to the results presented table.1. Also observed the single phase voltage, current, RMS voltage, current, and power both algorithm shown in Fig.12 to Fig.13 found the ANN controller consider better performance compare to V/F controller.

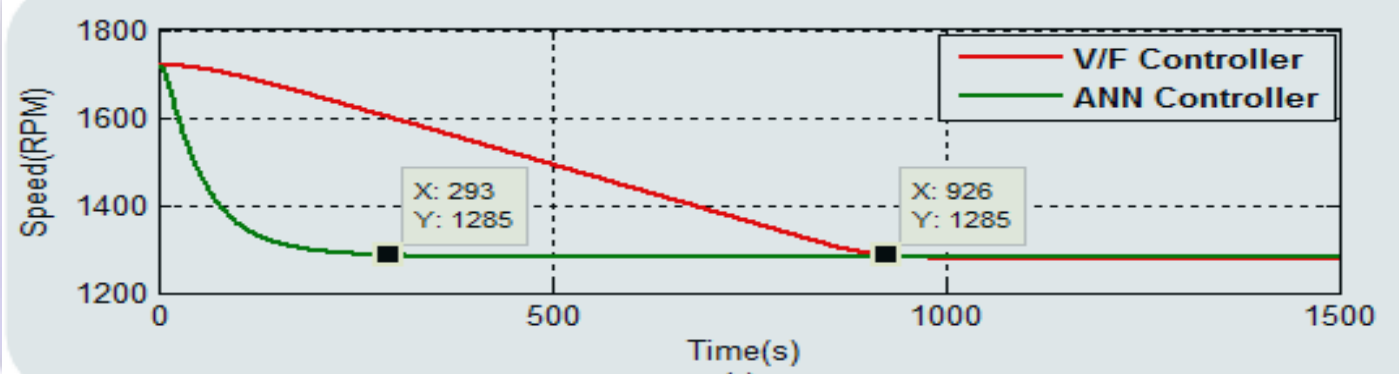

(a)

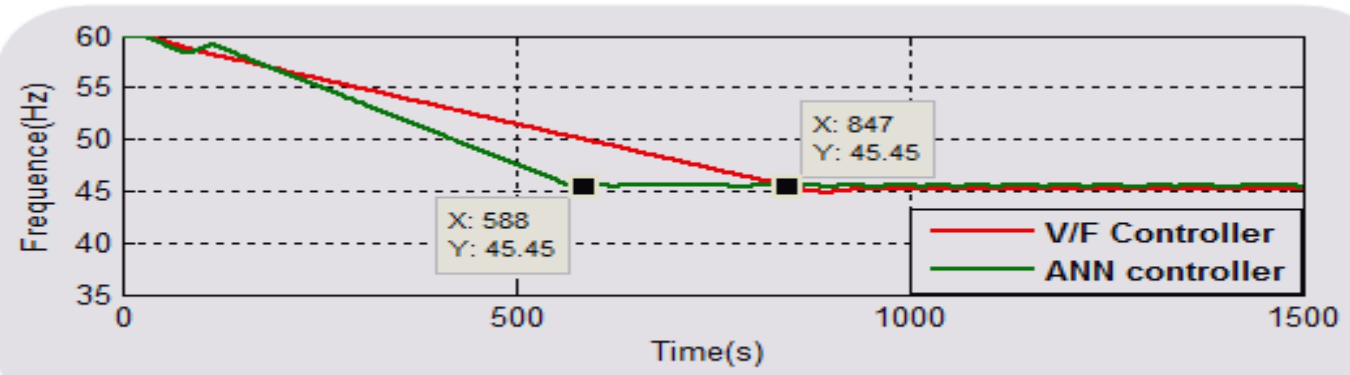

(b) 


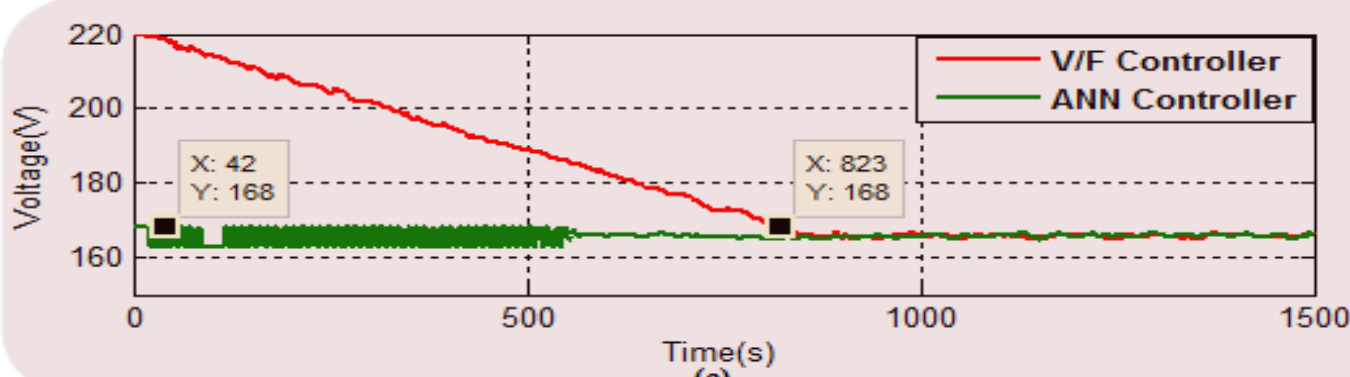

(c)

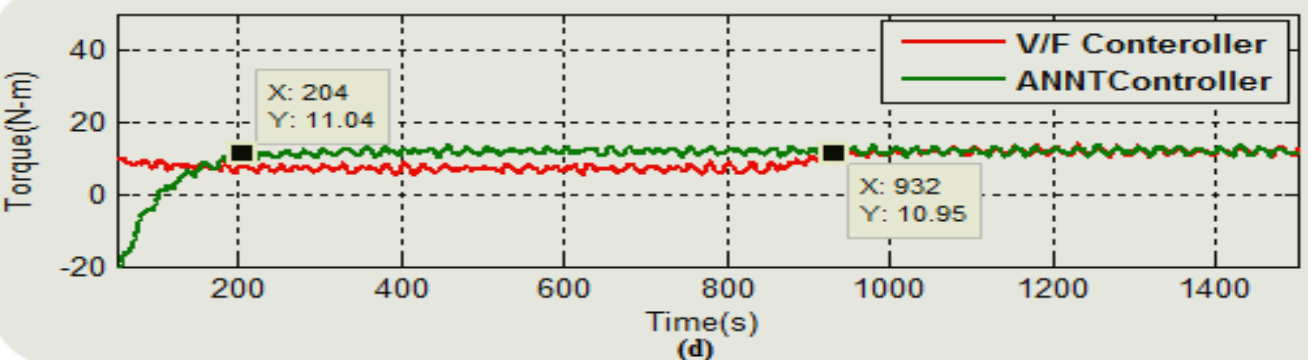

Fig.10 (a) Motor speed (b) motor frequency (c) Motor voltage (d) Torque

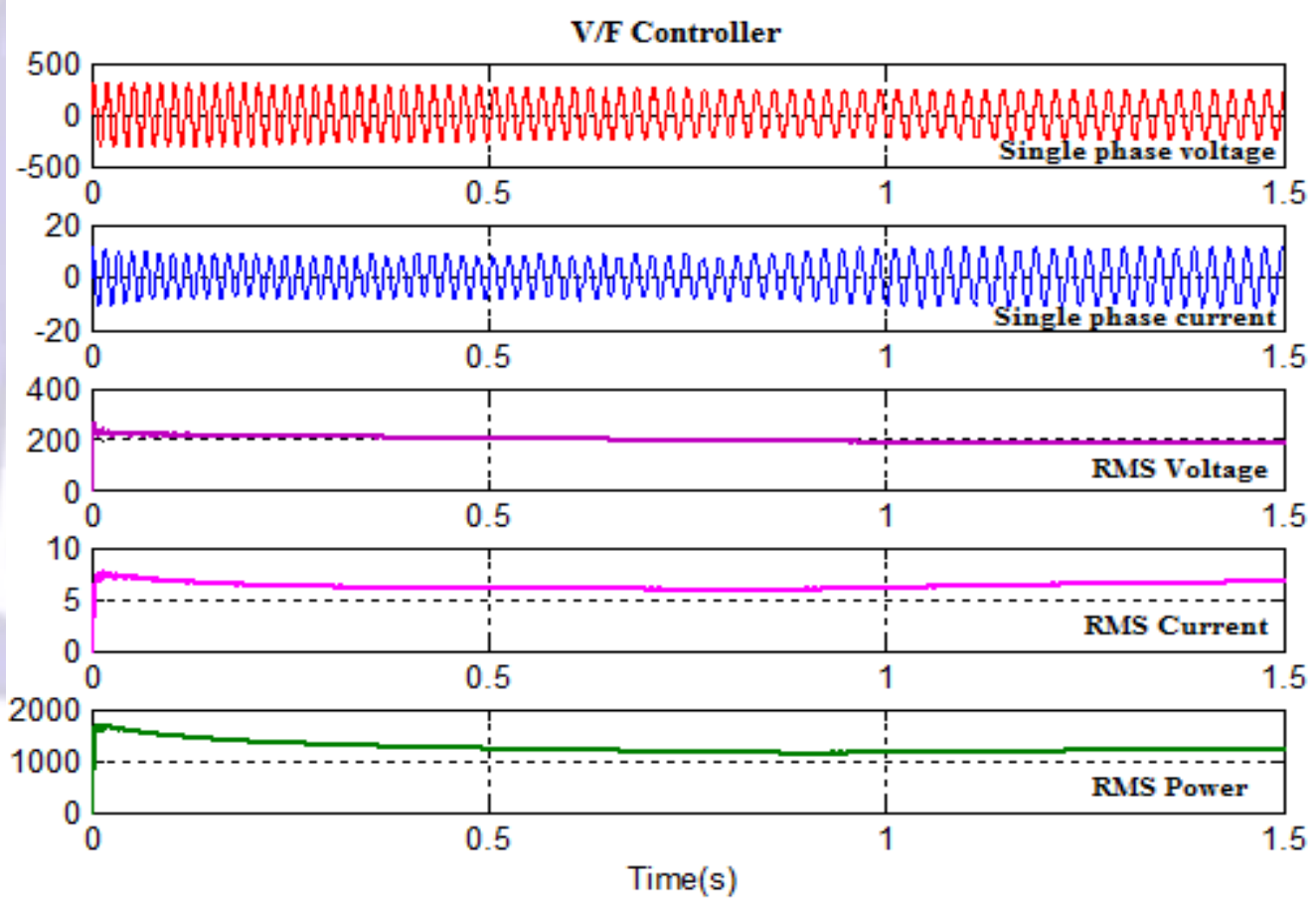

(a)

Fig.11 V/F Electrical parameter 


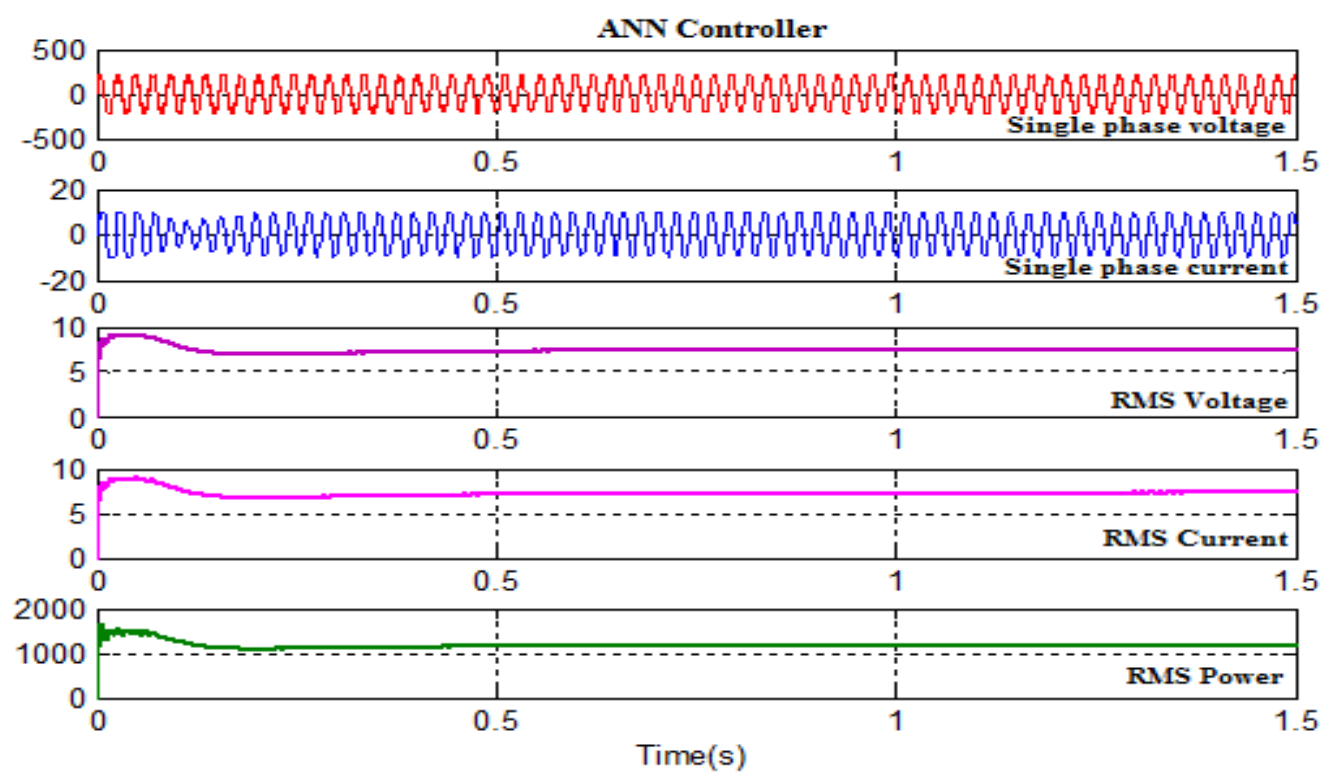

Fig.12 ANN Electrical parameter

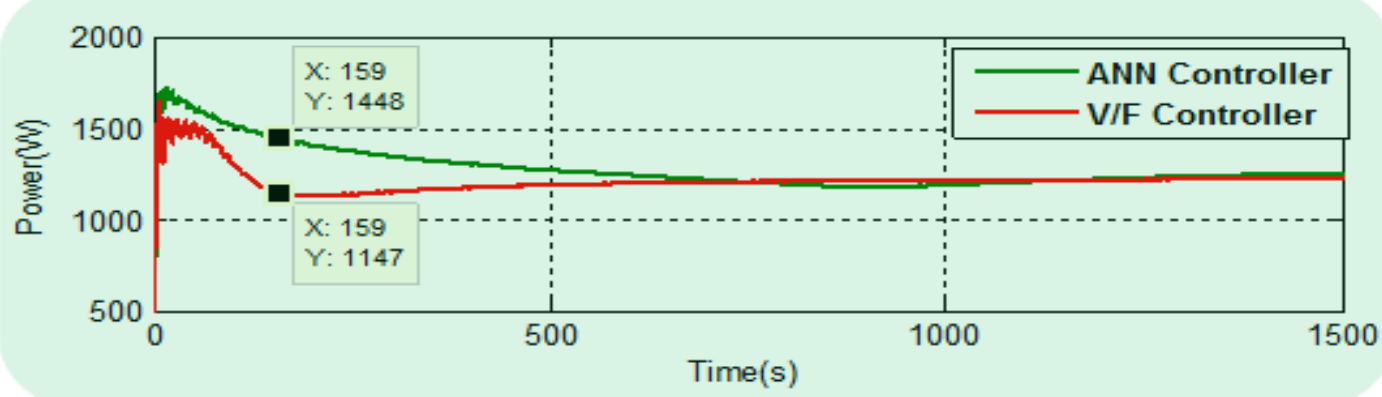

Fig.13 RMS power

Table.1 Simulation result

\begin{tabular}{|c|c|c|c|c|c|c|c|c|c|c|}
\hline \multirow{2}{*}{ Controller } & \multicolumn{2}{|c|}{ Speed } & \multicolumn{2}{|c|}{$\begin{array}{l}\text { Frequenc } \\
\text { y }\end{array}$} & Torq & & & \multicolumn{2}{|c|}{ Power } \\
\hline & rpm & $\mathrm{e}^{\operatorname{Tim}}$ & $\mathrm{Hz}$ & $\mathrm{e}^{\text {Tim }}$ & $\mathrm{N}-\mathrm{m}$ & Time & volts & Time & watts & Time \\
\hline $\begin{array}{l}\text { ANN } \\
\text { controller }\end{array}$ & $\begin{array}{l}128 \\
5\end{array}$ & 293 & 45 & 588 & $\begin{array}{l}11.0 \\
4\end{array}$ & 204 & 168 & 42 & 1448 & 159 \\
\hline $\begin{array}{l}\text { V/F } \\
\text { controller }\end{array}$ & $\begin{array}{l}128 \\
5\end{array}$ & 926 & 46 & 803 & $\begin{array}{l}10.9 \\
5\end{array}$ & 932 & 168 & 823 & 1147 & 159 \\
\hline
\end{tabular}




\section{ISSN $2321-807 x$ \\ Volume $12 \mathrm{Number} 9$ \\ Journal of Advances in Chemistry}

It was observed from the simulation results that by using the ANN control, for the set speed of $1285 \mathrm{rpm}$ the speed reaches its desired set value at 293 seconds, rated frequency 45.45 at 588 seconds, rated voltage 168 reached at 42 seconds, torque $11.04 \mathrm{~N}-\mathrm{m}$ at 204 seconds and power at steady state 1448 watts at 150 seconds respectively.

\section{CONCLUSIONS}

A systematic approach of achieving the speed control of an induction motor drive by means of ANN control strategy has been investigated in this paper. Simulink model was developed in Matlab with the ANN controller for the speed control of IM. The main advantage of designing the ANN coordination scheme is to control the speed of the IM \& to increase the dynamic performance \& to provide good stabilization. Simulations are run in Matlab and the results were observed on the corresponding values. Another advantage of this model is speed of operation whom the ANN is much faster than the other control strategies; specifically the tedious task of 3000 training of $\mathrm{PI} V / F$ and 3000 parameter analyzing functions are done in ANN with in a seconds. Collectively, these results show that the ANN controller provides faster settling times, has very good dynamic response and good stabilization compared to the $\mathrm{PI}$ $\mathrm{V} / \mathrm{F}$ control scheme. This shows the effectiveness of the designed controller \& the designed ANN controller tries to speed up the performance of the drive, thus showing faster dynamism. It is also observed that with the designed ANN controller, the response characteristics curves take less time to settle and reach the final steady state value compared to conventional controller. Further, it can also be observed that using the ANN control, the system stabilizes in a very less time compared to the other methods because of the training process of the ANN involved and the proper selection parameter.

\section{References}

[1] P. Gnacinski, "Energy saving work of frequency controlled induction cage machine, " Energy Conversion and Management, Vol. 48, 2007, pp. 919-926.

[2] Jinjie Huang, Shiyong Li, Chuntao Man, "A TS type of fuzzy controller based on process of input output data", Proc. of 42nd IEEE Conf. on Decision \& Control (CDC'03), Hawai, USA, pp. 4729-4734. Dec. 2003.

[3] Tamer, M.,"PID Control, Implementation and Tuning ",Published by InTech.2011.

[4] Gustavo, M. A., Valceres, V. R., Erivelton, G. N., and Ryuichi Y. ," Application of Genetic Programming for Fine Tuning PID Controller Parameters Designed Through Ziegler-Nichols Technique", ICNC 2005, LNCS 3612, Springer-Verlag Berlin Heidelberg, pp. 313-322, 2005.

[5] M. Perron, H. L. Huy, "Full load range neural network efficiency ptimization of an induction motor with vector control using discontinuous PWM, ” in Proc. IEEE Symp. Ind. Electron., vol.1, 2006, pp. 166-170.

[6] Kusagur, A., Kodad, S.F., and SankarRam, B.V.,"Al based design of a fuzzy logic scheme for speed control of induction motors using SVPWM technique", Int. Jr. Comp. Sci. \& Network Security, Vol. 9, No. 1, pp. $74-80,2009$.

[7] B. K. Bose, N. R. Patel, K. Rajashekra, "A neuro-fuzzy base on-line fficiency ptimization control of a stator flux oriented direct vector controllrd induction motor drive, " IEEE Trans. Ind. Electron., vol. 44, no. , 1997, pp. 270-273.

[8] Kim T. H., Maruta I., and Sugie T., "Robust PID controller tuning based on the constrained particle swarm optimization", Automatica, Vol. 44, Issue 4, Apr. 2008, p. $1104-1110$.

[9] Chong. Lin, Q.G. Wang and T.H. Lee, "Output tracking control for nonlinear via T-S fuzzy model approach, Proc. IEEE Trans. systems. Cybernetics, Vol. 36, No. 2, 2006.

[10] Khiar D., "Robust takagi-sugeno fuzzy control of a spark ignition engine", Control Engg. Practice, 2007.

[11] Ben-BrahimL.,"Improvement of the stability of the V/f controlled induction motor drive systems", IEEE Proceedings of the 24th Annual Conference, Vol. 2, pp. 859-864, 1998.

[12] J. Li, L. Xu, Z, Zhang, "A new efficiency optimization method on vector control of induction motor, " in Proc. IEEE Conf. Electrical Machines and Drives, 2005, pp. 1995-2001.

[13] Tunyasrirut, S., Suksri,T. and Srilad,S., "Induction Motor using Space Vector Pulse Width Modulation", Proc. of the World Academy of Science, Engineering Fuzzy Logic Control for a Speed Control of And Technology, Vol. 21, pp. 71 - 77, Jan. 2007.

[14] Faa-Jeng Lin, and Rong-Jong Wai,"Robust control using neural network uncertainty observer for linear induction motor servo drives", IEEE Trans. On ower Electronics, Vol. 7, No.2, March 2002, pp.241-251.

[15] Bose, B.K., "Modern Power Electronics and AC Drives", Pearson Education, Inc., India, 2002. 